\title{
La disputa en torno a la comunidad o la deriva antifundamentalista del continente habermasiano
}

\author{
MARÍA JOSÉ GUERRA PALMERO \\ Universidad de I a I.aguna
}

El protagonismo dado a la comunidad en el pensamiento habermasiano es innegable. No obstante, la caractcrización de ésta al modo de una intersubjetividad reconciliada y con un fuerte énfasis en lo consensual ha desencadenado las objeciones de aquellos/as que se muestran más sensibles a las demandas de la pluralidad y las diferencias. El objetivo es trabajar a favor de una adecuación del modelo ideal de comunidad a los requisitos que plan- tean las situaciones pragmáticas reales. De ahí que la crítica interna habermasiana - Benhabib, Wellmer y McCarthyhayan puesto el acento en la necesidad de retomar la cuestión del juicio moral - la atención a lo concreto y al contexto-la narratividad y el proceder hermenéutico como contrapartida a los excesos racionalistas y abstractivos del citado modelo habermasiano de comunidad universal de diálogo.

El individuo se ha construido negando la evidencia. El sujeto filosófico se constituyó al modo de las pétreas «estatuas pensantes» que nos refiere Elías ${ }^{1}$ y la teoría social moderna se cimentó en los presupuestos individualistas del «estado de naturaleza»: Adán estaba solo, Robinson también -luego, a posteriori, ya vendrían Eva y Viernes a perturbarlo todo-. Pero la autosuficiencia ha resultado quimérica, por lo menos, con la intensa radicalidad de los presupuestos de un individualismo posesivo. Ahora parece que enfrentamos la tarea de «quebrar» el aislamiento del individuo con relación a los otros. Curioso periplo paradójico: ¿qué necesidad había de aislar lo que previamente era coexistente y común, para después tener que emprender la tarea de tender puentes, de proponer vías de comunicación entre las que falazmente se autocomprendían como solitarias mónadas?

Tal «nccesidad» quizás viniera determinada por la emergencia de la conciencia moral individual como ganancia específica de la modernidad ${ }^{2}$, pero el problema radica en la falaz determinación de una autocomprensión autista de la subjetividad. Tras la hegemonía prestada al sujeto, pensar la intersubjetividad no ha sido, ni es, asunto fácil. Theunissen nos ofrece una revisión

' Véase N. Elías, «Las estatuas pensantes», en La sociedad de los individuos, Barcelona, Península, 1990.

${ }^{2}$ A. Wellmer, "Modelos de libertad en el mundo moderno", en C. Thiebaut (ed.), La herencia ética de la ilustración, Barcelona, Crítica, 1991, pp. 104-135. 
de las ontologías sociales de grandes pensadores de nuestro siglo donde la intersubjetividad parece heredar los tintes trascendentales ${ }^{3}$ y Dallmayr nos previene frente a los tratamientos «egológicos» de la misma intersubjetividad ${ }^{4}$. Los modos de tratar al sujeto se suelen «trasplantar», en nuestra cortedad conceptual, para dar cuenta de la intersubjetividad: la adecuación a la cosa no queda garantizada en modo alguno. El modelo más socorrido para conceptualizar la intersubjetividad redescubierta es el de la comunidad en sus distintas versiones. El peligro, que parece acechar a esta modelización de la complejidad relacional que designa la intersubjetividad, es el de primar lo "común", aquello que es compartido por todos, subestimando el papel de las diferencias no reductibles a un mínimo común múltiplo. Pero también hay que decir que la primacía otorgada al nudo comunitario soslaya y oscurece la trama abigarrada de vinculaciones que está a su base. El riesgo es que, ante la ausencia de modelos que den cuenta de lo complejo, nos conformemos con reescribir la intersubjetividad o bien como un agregado atomístico o bien como mera «transubjetividad» - en la estela de los «sujetos singulares colectivos»-, obviando que la condición misma de la intersubjetividad es la pluralidad y que lidiar con ella supone, a la vez, reconocer la paradójica condición de lo humano como «igualdad y distinción» ${ }^{5}$.

Habermas, como heredero del redescubrimiento del «mundo común»-que aprendió de Hannah Arendt por dónde debe comenzar una teoría de la acción-, no nos resulta lo suficientemente «arendtiano" en su consideración de la intersubjetividad. El motivo consensual fuerza a que la pluralidad devenga unidad. En este contexto, la unidad parece acompañar como su sombra al prejuicio (cuasi) trascendental. Nuestra pregunta es cómo desvincular trascendentalismo e intersubjetividad y si esto lo logra la versión habermasiana de la comunidad recurriendo a una «pragmática universal» que, explícitamente, pretende alejarse de la propuesta dura de Apel.

Dejando de lado las objeciones de Apel a Habermas - en las que le recrimina su «inconsistencia» por el trato ambivalente que proporciona a las dimensiones empíricas y trascendentales de la misma comunidad-, transitaremos hacia criticas que operan en sentido contrario - especialmente las de Benhabib y Wellmer-. Éstos optan por proseguir la estrategia del «debilitamiento»o disolución de los restos trascendentales aproximando lo racional-reconstructivo

${ }^{3}$ Véase M. Theunissen, The Other. Studies in the Social Ontology of Hussserl, Heidegger, Sartre and Buber, Cambridge, Mass., MTT Press, 1986.

${ }^{4}$ Como serían el de Husserl o el de Sartre. Véase F. Dallmayr, Twilight of Subjectivity. Contributions to a Post-Individualist Theory, The University of Massachusetts Press, 1981. Dallmayr apunta que su objetivo es cuestionar el «antropocentrismo» y las connotaciones «egológicas» y «posesivas» del individualismo.

s Hannah Arendt es la que nos proporciona las claves que servirán para que autores como Wellmer y Benhabib desafien el modelo habermasiano de comunidad ideal ceñida al «imperativo del consenso". La atención a la pluralidad como condición misma de la intersubjctividad y el acceso narrativo a la identidad marcarán la diferencia, Véase $\mathrm{H}$. Arendt, La condición humana, Barcelona, Scjx Barral, 1974. 
habermasiano a lo hermenéutico, sin abdicar por ello de la pretensión normativa de una teoría crítica que ya no necesitaría de idealizaciones plenas y redondas. En esta deriva del «habermasianismo», la inspiración arendtiana será retomada de la mano de la reivindicación de la kantiana «facultad de juzgar» ${ }^{6}$.

Pero, ¿cómo librarnos del lastre trascendental sin tirar con el agua del baño al bebé, en este caso a la normatividad? Ésta es la pregunta a la que la «crítica interna» - Wellmer, McCarthy y Benhabib - pretende contestar. Seyla Benhabib se desdice de la misma cuasi-trascendentalidad que reivindica Habermas, para aproximar su programa reconstructivo racional a lo hermenéutico-narrativo. McCarthy cuestionará, a su vez, la «superación de la hermenéutica» supuestamente llcvada a cabo por Habermas ${ }^{7}$ y arbitrará vías para una «pragmatización» de la teoría crítica. $Y$ Wellmer propiciará el desenganche de la ética discursiva de fundamentaciones últimas y de reconciliaciones intersubjetivo-comunitarias que reediten la nostalgia del absoluto ${ }^{8}$. Al desgranar las objeciones de estos autores, caeremos en la cuenta de que algo se mueve en la teoría crítica: una convergencia que, frente al exceso de celo idealizador, apuesta por la pragmática real. El problema de la aplicación no será por más tiempo desdeñado y señalará la recuperación, vía Hannah Arendt, del legado kantiano del juicio reflexionante. La intersubjetividad dejará de lado el corsé transubjetivo y se reconocerá en la irreductible pluralidad, que es su misma condición de posibilidad.

En lo que sigue, tomaremos nota de las líneas maestras de la desidealización y de la desfundamentación de la comunidad operada por Wellmer y Benhabib, que, en ocasiones, parecen desplegarse en paralelo. De lo que se tratará es de disipar los restos trascendentales en dirección a una pragmática real. $\mathrm{La}$ lectura de Hannah Arendt del juicio kantiano ofrecerá, como ya anunciábamos, la posibilidad, dentro del marco moderno, de desidealizar la comunidad y prestar atención a los otros reales. Desgranemos algunos episodios de este decurso.

\section{Contra la intersubjetividad reconciliada: los títulos de la pluralidad}

Wellmer desde una perspectiva «kantiana» ${ }^{9}$ acepta la reformulación dialógica del universalismo, pero objeta tanto las premisas teórico-consensuales como los intentos de fundamentación. Reconoce que tanto «las construcciones con-

- Tanto Benhabib como Wellmer retoman el sentido de la inconclusa reflexión arendtiana sobre el juicio kantiano y su virtualidad ético-política con el fin de optar a una forma intersubjetiva de validez - la «mentalidad ampliada»- que deje atrás idealizaciones comunitarias y remita a los contextos reales de discusión. Parte de las reflexiones de Arendt sobre el juicio las podemos encontrar en las páginas finales de La vida del espiritu, Madrid, Centro de Estudios Constitucionales, 1984.

"T. McCarthy, «Razón y racionalización: la "superación" de la hermenéutica por Habermas", en Ideales e llusiones, Madrid, Tecnos, 1992, pp. 139-163.

${ }^{8}$ A. Wellmer, Etica y dialogo, Barcelona, Anthropos, 1994, pp. 124 y ss.

'A. Wellmer, Ética y diálogo. Elementos del juicio moral en Kant y en la ética del discurso, 
ceptuales formalistas e idealizantes de la teoría del consenso» como «... la intención de derivar una ética universalista directamente... a partir de estructuras de la razón, es decir, sin pasar por la instancia mediadora de una historia de la conciencia moral» ${ }^{10}$ son «inconfundiblemente kantianos». Al mismo tiempo cree necesario, como Benhabib, no eludir las críticas hegelianas a Kant - dando un rodeo para evitar su sistema - que obligan a rechazar la interpretación teórico-consensual de una ética universalista dialógica y a desestimar el fundamentalismo unidimensional y fuerte. De lo que se trata es de debilitarlo en base a una pretensión pluridimensional y débil.

El empeño crítico de Wellmer desembocará en «una reconstrucción falibilista de la ética del discurso» " que pone en cuestión «... una edificación filosófica apuntalada sobre los pilares de un ideal, ideal que en el caso de Kant es el reino de los fines, y en el de Apel y Habermas una situación ideal de comprensión mutua».

Lo que está en cuestión es la idealidad misma de una comunidad ilimitada de comunicación. Si la maniobra de Habermas respecto a Apel era de debilitamiento, Wellmer no la cree suficiente y se empeña en rebajar aún más la trascendentalidad. Se trata de renunciar a los residuos metafísicos encarnados en el estado de reconciliación plena de la comunidad y en la pretensión fundamentalista, con tal de desechar, de una vez por todas, el miedo al escepticismo, reasumiéndolo como un momento de la razón ${ }^{12}$. Wellmer junto a Benhabib engrosan las filas de los «descontentos» con la programática habermasiana y su estrategia ideal-abstractiva ${ }^{13}$,

Si el escepticismo se reasume como momento de la misma razón, se viene abajo el escenario polémico que Habermas montaba en Ética del discurso. Notas sobre un programa de fundamentación. La intención de Wellmer es que demos al traste con las «premisas harto problemáticas de la teoría consensual de la verdads ${ }^{14}$ porque ahogan la pluralidad constitutiva de la comunidad humana. El mismo aliento pluralista que animará el esfuerzo crítico de Benhabib, deudor de la reivindicación que de la pluralidad hace Hannah Arendt, lo encontramos en Wellmer.

ed. cit, pp. 37 y ss. Wellmer piensa «con Kant contra Kant» al tiempo que no hace desmerecer lo acertado de las objeciones hegelianas. Como estamos viendo, Kant da para mucho como potencial inspirador, incluso en sentidos contrarios. Valga como cjemplo frente al pathos formalista y consensual de Apel y Habermas, el énfasis antiformalista y disensual de Javier Muguerza. Para una visión de los rendimientos plurales de Kant en el contexto al que estamos atendiendo véase C. Thiebaut, «De nuevo Kant: de norma a principio, de principio a proceso», epígrafe de «Los límites del procedimentalismo en la reformulación del programa ético modernom, contenido en Los limites de la contunidad, Madrid, Centro de Estudios Constitucionales, 1992, pp. 183-193.

10. Wellner, Etica y diálogo, p. 38.

"Op. cit., p. 143.

12 Op. cit, p. 41.

13 Véase, como juicio critico sobre Wellmer, A. Ferrara, "Critical Theory and its Discontents: On Wellmer's Critique of Habermas», en Praxis International, núm. 8, 1987, pp. $246-267$.

${ }^{34}$ A. Wellmer, op. cit., p. 40. 
Muguerza recriminaba a Apel por no haber partido, ahorrándose «por lo menos la mitad del trayecto recorrido en su transformación» ${ }^{15}$, del «nosotros» del «reino de los fines» de la Fundamentación de la metafísica de las costumbres; pero ahora Wellmer se desprende de la trascendentalidad de este "nosotros» kantiano transitando a la tercera de las Críticas. Haciendo uso de la interpretación arendtiana de las «máximas del sentido común» se detecta la similitud estructural entre el juicio político y moral, y el juicio estético, y se trae a primer plano a la misma pluralidad:

«El juicio para Hannah Arendt está intrínsecamente relacionado con la esencial pluralidad de los seres humanos, con nuestra vida en un mundo común, que como mundo común se abre por el habla. Las cuestiones de la praxis, que pertenecen a este mundo común, no son susceptibles de prueba científica; no son cuestiones de conocimiento, sino de opinión" ${ }^{16}$.

Lo realmente interesante es esta nueva lectura del imperativo categórico que «... exige, de acuerdo con su propio sentido, una transición hacia diálogos reales: sólo en un medio de mensajes y discursos reales puede dilucidarse si yo me he colocado de la manera adecuada en el lugar de los otros o no" ${ }^{17}$.

Si bien no podemos forzar la ética kantiana hasta el punto de entenderla como «ética dialógica» - «el principio del diálogo sustituye al principio moral»- ${ }^{18}$, sí podemos interpretarla como «ética del diálogo» - tal principio ocupa «un puesto privilegiado entre los principios morales derivados»-. La virtualidad de esta interpretación reside en que pone sobre el tapete como "problemas" — «descuidados por Kant» y desconsiderados por Habermas como no estrictamente morales-, kla pluralidad fáctica de perspectivas sobre valores y necesidades». Wellmer cree «... posible un esclarecimiento dialógico de las diversas interpretaciones de una situación dada y de las relaciones del individuo consigo mismo, y cada vez que se pueda alcanzar un entendimiento comunicativo acerca de las múltiples apreciaciones sobre necesidades y valores, ello constituirá también una exigencia de la ética kantiana».

Señala así la «infraestructura comunicativa» relativa a cómo comprendemos las situaciones, a cómo nos comprendemos a nosotros mismos y a cómo comprendemos «las perspectivas ajenas sobre valores y necesidades». Ahora, a partir de Kant y contradiciendo su desatención a esta «infraestructura», se trata de considerar la corrección de la formación de los juicios morales que, indudablemente, depende de las definiciones que hagamos de las situaciones, a la vez que de nuestras comprensiones y uautocomprensiones». Al fin y al cabo, como apunta Taylor, somos self-interpretating's animals.

is J. Muguerza, «Sobre la condición "metafísica" y/o "postmetafísica" del sujeto moral», en M. Herrera (comp.), Jürgen Habermas. Moralidad, ética y política, Alianza, México, 1993, p. 177.

16 A. Wellmer, "Hannah Arendt on Judgment: The Unwritten Doctrine of Reason (1985)", en Endspiele. Die unversöhnliche Moderne, Frankfurt, Suhrkamp, 1993, pp. 309-332, p. 310.

"A. Wellmer, op. cit., p. 73.

${ }^{12}$ Op. cit., p. 74. 
Los términos en que se desarrolla la crítica a la idealización y a las premisas teórico-consensuales comprometerán al mismo concepto de racionalidad. Ésta se apeará de la formalidad y remitirá a unuestras interpretaciones, creencias y comprensión de nosotros mismos» ${ }^{19}$, las cuales pueden ser más o menos «racionales»-《adecuados, fundados, correctos o incluso, veraces»-. La racionalidad, más que atribuirse en exclusiva a las propiedades formales del discurso, se predicara de nuestras apreciaciones de nosotros mismos, del mundo y de las situaciones ajenas. La identidad vuclve con renovada vitalidad a la palestra.

Entendiendo a esta luz la dimensión discursiva de la moral no necesitamos una teoría consensual de la moral, ya que podríamos entender falibilísticamente la anticipación de consensos morales. Wellmer pone de manifiesto las paradojas a que conduce la oposición entre las condiciones ideales y las reales del discurso, "oposición a la que cabría calificar de consustancial al postulado U», que tan sólo es una «secuela directa de las premisas teórico-consensuales» ${ }^{20}$. De esta estrategia crítica se sigue la puesta en la picota de la «situación ideal de habla», pues, respecto de la racionalidad, no lo es todo la «estructura» y la «forma» ${ }^{21}$. La racionalidad de los consensos «dependerá de la apreciación que hagamos del acierto de nuestras razones», dependerá de nuestro «buen tino»:

«... la verdad no se sigue aquí de la racionalidad del consenso, sino de lo acertado de las razones que yo pueda esgrimir en favor de la pretensión de validez correspondiente, razones de las que ya debo estar convencido antes de poder hablar de la racionalidad del consenso».

El que tales razones, a posteriori, se revelen como «insuficientes» no «podría significar lo mismo que el estimar que un consenso anterior no era racionals, al no estar dadas «las condiciones de simetría y liberalidad propias de la situación ideal de habla» ${ }^{22}$. El recurso pragmático estricto no es suficiente para garantizar la racionalidad del consenso logrado. Tendremos, al menos, que contar con el «buen tino de todos los involucrados», condición necesaria a sumar a los rasgos estructurales de la situación ideal de habla. La determinación mcramente formal de la racionalidad revela su debilidad al soslayar el contenido.

Siguiendo la senda crítica contra los excesos idealizadores, Wellmer ataca directamente, tanto a la apeliana comunidad ideal de comunicación, como a la situación ideal de habla habcrmasiana en el doble sentido de que se asumen como estuposición necesaria y constitutiva de la situaciones argumentativa» ${ }^{23}$ y como eideal concebido en un sentido futurista, o sea, una idea regulativa»:

\footnotetext{
Op. cit., p. 94.

${ }^{*}$ Ibid.

"Op. cit., p. 95.

"Op.cit, p. 96.

${ }^{22}$ Op. cit., p. 106.
} 
«... la idealidad de las condiciones del discurso no podrá garantizar la verdad de los consensos mientras éstos sean particulares (es decir, finitos y empíricos) ni nos eximirán de examinar las razones que avalan los consensos».

Tal idealización comunitaria viene «a parar en nada» y más bien parece una invocación «a un locus futuro de una verdad definitiva y absoluta, a la idea de un lenguaje último» y a un estadio en que «la humanidad se haya tornado plenamente transparente ante sí misma ${ }^{24}$.

La denegación de la comunidad ideal se conjuga con la crítica de Wellmer al apuntalamiento genealógico y sociológico de esa misma comunidad. La clave aquí es el recurso a Durkheim. Habermas va más allá de la teoría pragmática del significado para justificar el enraizamiento de la moral en el lenguaje y recurre a una suerte de estrategia genealógica que afirma que, en el principio, era la comunidad. No sólo el lenguaje es una realidad moral, también lo es la misma sociedad. De esta manera sitúa «las fuentes de la validez del "deber ser" moral en una esfera pre-racional y simbólicamente estructurada de lo sacro», dando por supuesto un "consenso normativo primigenio». Señala así el sustrato sobre el que actuará la «lingüistización de lo sacrom, que evolutivamente des-diferenciará las pretensiones de validez normativas que toman su raiz en tal consenso originario. Habermas coloca, al principio de la historia, una conciencia identitaria colectiva, fuente de todo el cúmulo de obligaciones sociales y/o morales que logran la cohesión social. Wellmer apunta certeramente que aquí la idealización también funciona retroactivamente e impregna el aconsenso normativo originario y simbólicamente estructurado" que se convierte en "paradigma de todos los conceptos de validez» ${ }^{25}$. La propuesta de Habermas se estima como «fascinante ilación de ideas» que tiene la finalidad de «enraizar el "deber ser" moral en las estructuras generales de la comprensión lingüística, de manera tan firme que la pregunta acerca del sentido racional del mismo ya no tendría sentido ${ }^{26}$.

El recurso genealógico se revela problemático al recrear las premisas teórico-consensuales que suponen un obstáculo para una ética del discurso que asuma «un concepto de racionalidad pluralista» que no sea tributario de fundamentaciones últimas ni que dependa de reconciliaciones definitivas ${ }^{27}$. Wellmer pone por delante el presente, es decir, la referencia a «un núcleo racional

${ }^{24}$ Op. cit, p. 107.

${ }^{25}$ «El consenso normativo que se articula como esfera de lo sacro es el prototipo de un acuerdo idealizado y de una intersubjetividad otientada a una comunidad ideal de comunicación, $\mathrm{y}$, por ende, el prototipo de toda validez intersubjetiva posible» (op. cit., p. 170).

${ }^{26}$ Se desmonta la estrategia genealógica habermasiana de apuntalamiento independiente de la comunidad ideal de comunicación a partir de argumentos tomados del mismo Habermas, de su consideración sobre la concepción mítica desdiferenciada e incapaz de reflexividad que dificilmente puede apelar a la obligación moral: "El hecho de que en las sociedades primitivas exista una conciencia nomativa afectivarnente saturada nunca podrá abonarse sin más en la cuenta de la morals (op. cit., p. 175).

"Op. cit., p. 178. 
e insoslayable de problemas y posibilidades presentes en las sociedades modernas» ${ }^{28}$ junto a "todas las experiencias patológicas, irracionales, inhibidoras e inhumanas que nos suele deparar" ${ }^{29}$, y relega a la comunidad ideal de comunicación tanto en su proyección futura como en su idealizada retroyección pasada. La validez moral de «debe» no debe ser cortada al talle de la validez veritativa y, más que «el respaldo de la autoridad de lo sacro», requiere un «adiestramiento - tanto cognoscitivo como afectivo- en prácticas de reconocimiento mutuo».

Pasemos ahora a ver alguno de los efectos de la terapia desidealizadora y desfundamentadora sobre la misma ética discursiva. En primer lugar, Wellmer, al igual que hará Benhabib, dinamita el «puente» habilitado por «U» entre las presuposiciones de la argumentación y la moral universalista: «las normas argumentativas gencrales... no son normas morales universalistas ni metanormas de la moral» ${ }^{30}$. En segundo lugar, se señalará una falla moral grave de la misma ética discursiva: el protagonismo dado a la racionalidad de los «buenos argumentos» no conlleva el reconocimiento moral a las personas. La «dimensión moral de la argumentación no se puede explicar partiendo de la orientación validatoria del discurso" ${ }^{31}$. El «deber ser» argumentativo, dice Wellmer, es "periférico", pues «las morales atañen al reconocimiento de personas». En tercer lugar, se concluye que la regla de exclusión para aquellos que no acceden a la competencia comunicativa no es de recibo: "es un requisito de la moral otorgar el derecho de palabra también a quienes aún no pueden argumentar bien» ${ }^{32}$. La obligación argumentativa vinculada a la racionalidad no equivale exactamente a la obligación moral hacia las personas al margen de la consideración de sus argumentos. Es necesario «desvincular» a los argumentos de las personas - evitando las falacias ad hominem-, pero distorsionamos esta operación si la entendemos «como anticipación de un estado ideal que debe ser materializado por la comunidad real de comunicación». Por último, y de la misma manera, se nos escapa el sentido de la inevitable presuposición de significados intersubjetivamente compartidos si la entendemos como anticipación de un lenguaje último e ideal. Wellmer coincide con el juicio de Victoria Camps de que:

«... nos equivocamos accrca del sentido de la necesidad de estas presuposiciones si las hipostasiamos hasta convertirlas en ideales de la realidad, aunque esta apariencia engañosa tenga su raíz... en el propio lenguajes ${ }^{33}$.

${ }^{2 s}$ Op. cit., p. 179.

${ }^{20}$ Op. cit., p. 180.

${ }^{29}$ Op. cit., p. 126.

" «... la obligación de no soslayar ningún argumento... no tiene ninguna repercusión directa sobre la pregunta de cuándo, cómo y con quién tengo la obligación de argumentar» (op. cit, p. 128).
${ }^{32}$ Op. cit., p. 130.
"* Op. cit., p. 134. 
El camino directo que va de la argumentación a la moral es un espejismo.

\section{Denunciando la «falacia racionalista»}

Benhabib, paralelamente a Wellmer, cree que lo que cstá en juego es el estatuto cuasi-trascendental de la racionalidad comunicativa. La reconstrucción racional «sustituye» al viejo sentido de la autorreflexión y sanciona la colaboración entre filosofia y ciencias sociales ${ }^{34}$. Habermas pretende «continuar» la filosofía trascendental con otros medios, apelando a los «patrones de competencia» que evolucionan en la historia del individuo y de la especie.

Si dejamos a un lado los presupuestos evolucionistas ${ }^{35}$, el trascendentalismo débil habermasiano hace gala de vocación falibilista ${ }^{36}$. Sin embargo, ésta queda, en parte, arruinada al pecar Habermas de un excesivo teoreticismo que margina la cuestión práctica de la «ruptura emáncipatoria»: «la dificultad... es que parece un resultado natural del presente ${ }^{37}$ si se satísfacieran, sin más, los cánones de la racionalidad comunicativa y comunitaria. Benhabib cree, en cambio, que no hay inexorabilidad alguna que invocar: nada garantiza que el legado moderno se realice por sí solo. La reminiscencia, vía evolucionismo, de la filosofía especulativa de la historia es rechazada de plano. Pero veamos cómo funciona, en este caso, la maquinaria des-idealizadora.

No se renuncia a la pretensión crítica, tan sólo se la traslada al enjuiciamiento de los contextos reales. La «falacia racionalista» que comete Ilabermas es deudora de la desatención a las contingencias situadas en los inicios y finales de los discursos. No debemos suponer la naturaleza autogenerativa de la razón. Es más, debemos moderar la inclinación al excesivo cognitivismo y recuperar la dimensión narrativa como relevante. Es imprescindible poner en cuarentena a la teoría consensual de la verdad en lo que afecta a la validez normativa, sin que tal prescripción menoscabe el concepto de razón discursiva que remite a la comprobación pública y argumentativa.

El programa fundacionalista es insostenible: no se sostiene la conexión «cuasi-trascendental» entre una ética comunicativa y las bases del habla racional.

\$. S. Benhabib, Critique, Norm and Utopia, New York, Columbia University Press, 1986, p. 256.

3s Op. cit, p. 277. Benhabib lamenta que restos de mala filosofía de la historia, aun atenuados, se cuelen en las reconstrucciones habermasianas. En este sentido se muestra de acuerdo con la denuncia postmodema de las metanarrativas. Vease S. Benhabib, «Epistemologies of Modernism: a Rejoinder to Jean Francois Lyotard", en L. Nicholson (ed.), Feminism/Postmodernism, London, Routtcdge, 1990 , p. 125. Las criticas al evolucionismo habermasiano son moneda corriente. Véase, por ejemplo, A. Giddens, «¿Razón sin revolución?», en Giddens y otros, Habermas y la modernidad, Madrid, Tecnos, 1988, y F. Dallmayr, "Habermas on Human and Social Development» $y$ «Some Critical Comments», en Twilight of Subjectivity, ed. cit., pp. 179-210.

${ }^{36}$ «... si podemos mostrar que los criterios de la racionalidad comunicativa son los resultados de los procesos de aprendizaje que pueden ser reconstruidos significativamente, entonces su estatus "cuasi trascendental" puede ser considerado» (S. Benhabib, op. cit., p. 265).

"Op. cit., p. 277. 
No tiene sentido pensar que la interpretación procedimentalista salva al programa fuerte de fundamentación. La mala circularidad que encarna la «situación ideal de habla» es desafiada. El compromiso universalista es previo y funciona como supuesto:

«La pragmática universal atiende a un nivel de abstracción tal que cada individuo es considerado como un ser capaz de consenso. Ésta es una asunción altamente contrafáctica, que ya asume una actitud moral que se corresponde con un punto de vista ético universalista que desatiende todas las diferencias naturales y sociales como irrelevantes al definir el núcleo moral de la propia humanidad. Esto significa que la pragmática universal reconstruye un sistema de reglas que será reconocida como vinculante por agentes de una cierta clase. Éstos han logrado, o pueden lograr, un nivel de Bildung práctica y moral que corresponde al nivel de abstracción moral y universalismo desde la que esta teoría procede» ${ }^{38}$.

Los supuestos antropológicos que inciden en la delineación abstracta y formal de la situación ideal de habla remiten al homo cooperante - agente cstrictamente racional-, que reconoce el interés común y colabora así en su consecución. La entraña universalista es «presupuesta metodológicamente» ${ }^{39}$ : «Uno extrae de la sítuación ideal de habla lo que previamente había puesto en ellas ${ }^{40}$.

Más concretamente, Benhabib piensa que no hay ninguna necesidad de que la ética comunicativa invoque el principio de universalización: «no está claro lo que el principio de universalizabilidad añade al proceso argumentativo» ${ }^{41}$. Tal metanorma predeterminada parece contradecir el mismo primado del diálogo discursivo, pues ino podría el mismo principio consensual ser revocado por consenso? El asunto, desde la reformulación de las objeciones hegelianas a la ética del discurso, es que «U», o bien es una tautología, o bien conlleva «asunciones materiales normativas», pues «las así llamadas presuposiciones "universales" pragmáticas del discurso humano" no pueden sostenerse al margen de un «contenido histórico-cultural». ${ }^{42}$.

Especial relevancia tiene la alusión de Benhabib, que se suma a la de Wellmer, a las «reglas de exclusion" que implícitamente «trabajan prejuzgando» el contenido de la teoría moral. Quedan fuera «aquellos que no hablan» - niños, locos, animales-, con lo que nuestras relaciones con ellos dejan de ser «morales». La moralidad y su espectro sólo juega a la horizontalidad; las relaciones "verticales" quedan fuera. Sólo cuentan los "participantes adultos responsables e iguales» ${ }^{43}$ en la tradición del contrato. Esta consideración predetermina qué se entiende por lo moral, pues «la incontrovertibilidad de $\mathrm{U}$ ha sido ya prein-

\footnotetext{
${ }^{38}$ Op. cit., p. 291.

${ }^{39}$ Op. cit., p. 291.

${ }^{40}$ Op. cit., p. 293.

"Op. cit., p. 301.

${ }^{42}$ Op. cit. p. 306.

${ }^{43}$ Op. cit. p. 307.
} 
terpretada a la luz de asunciones materiales normativas». Pero es que, además, desentrañar el significado del «interés común» implica abrir la puerta a «factores» culturales, sociológicos o psicológicos ${ }^{44}$. U queda tocado de muerte: «la presencia de un principio de universalizabilidad en la ética comunicativa o es redundante o inconsistente». Estas objeciones no afectan a D, al presupuesto discursivo. La reversibilidad dialógica es suficiente, desde el punto de vista de Benhabib, para sustituir a la universalizabilidad. A la luz de esta estimación de la "situación ideal de habla» y del papel de "U» en la ética discursiva, se enfatiza el papel de «asunciones adicionales» implícitas que conllevan materialidad y, por tanto, contaminan la pureza de la forma presupuesta. La falacia racionalista se comete cuando la continuada autorreflexión crítica sobre las condiciones de posibilidad de la razón, condiciones nunca enteramente determinadas por la razón misma, son minimizadas. Se invocan así sus poderes autogeneradores, sin reconocer su enraizamiento en la contingencia. No son soslayables ni las historias de vida individuales, ni los patrones colectivos de memoria, aprendizaje y experiencia. La tradición de los modernos sostiene a la misma racionalidad. Lo que cuenta, no obstante, es algo más que sus características formales: no podemos obviar el «despliegue narrativo de las tradiciones históricas» ${ }^{45}$.

La disposición al consenso, a la restauración de la «intersubjetividad reconciliada" -que presupone hacer abstracción de las posiciones sociales reales-, no puede considerarse como panacea. Para Benhabib es absolutamente legítima la decisión moral de no participar en un discurso en el que el llamado a la "reconciliación» enmascara las «constelaciones existentes de poder». De lo que se trata es de preservarse de la complicidad con toda suerte de «universalismos sustitucionalistas» y de apostar por la realización de un universalismo que no traicione su nombre y que exigirá cuando convenga el disenso.

Las desigualdades estructurales y la inexistencia de reconocimiento reciproco anulan el modelo discursivo de resolución de conflictos, pues de lo que se trata es de lograr la «aplicación del ideal discursivo a las situaciones reales de vida", que vuelva a poner sobre el tapete la «mediación» entre una moralidad abstracta y universal y la eticidad. Esta mediación reclama, como en el caso de Wellmer, las funciones del «juicio moral».

\section{El trasvase al «uicio»}

El punto de partida de la crítica de Wellmer a Habermas era una reconsideración del programa kantiano, que inclinándose arendtianamente ${ }^{46}$ hacia la Crítica

Op. cit., p. 191.

${ }^{45}$ Op. cit., p. 320.

*6 Véase A. Wellmer, «Hannah Arendt on Judgment: The Unwritten Doctrine of Reason» (1985), en A. Wellmer, Endspiele. Die unversohnliche Modeme, ed. cit., pp. 309-332. 
del Juicio, buscaba prestar plausibilidad a la dirección ético-dialógica en el mismo Kant. De lo que se trata es interpretar el imperativo categórico a la luz de las «máximas del sentido común», especialmente de aquella que prescribe: «Pensar colocándose en el lugar de todos los demás.» Al promover «un cambio de perspectiva hipotético», que nos conducirá a "entender» a los demás, la universalizabilidad de las máximas pasa a depender de una reflexión previa acerca de "la validez de las perspectivas ajenas sobre valores y necesidades» ${ }^{47}$. Debo incorporar a los otros «reales» en mi proceso de dilucidación reflexiva: la barrera entre lo moral y lo ético cae así estrepitosamente.

Hannah Arendt estimaba que, tras leer las dos primeras Críticas, el transitar a la Crítica del Juicio suponía encontrar a las «criaturas terrestres» ${ }^{48}$. Este remitirnos a los otros reales, que no ideales, supone nada menos que reconocer que «mi» reflexión es hipotética y falible. Me puedo equivocar respecto a los otros y, en consecuencia, debo dialogar con el otro «real» para comprobar lo acertado de mis conjeturas. Se dibuja así una forma de transitar del «yo al nosotros» que deja atrás la ficcionalidad idealizadora. Transitamos, de este modo y sin dilaciones, a la pragmática real.

El reconocimento de la contingencia en cuanto a «la voluntad y la capacidad de los individuos» para adoptar el punto de vista moral, su «sagacidad» moral y su visión política para trasladar los principios de la ética discursiva a la acción, son los requisitos para no reducir a la ética dialógica a la inanidad ideal, una vez que disolvemos la «falacia racionalista» y su insensibilidad hacia los contextos reales. La interpretación arendtiana del juicio kantiano predetermina la dirección de la critica de Benhabib a un Habermas obstinado en olvidarse del problema de la aplicación. Frente a esta obstinación, y en contexto polémico que alimentan no sólo los comunitarismos o el postmodernismo, sino también el feminismo, Benhabib delineará su alternativa «situacionista» que dovuclve el protagonismo soslayado a la contextualidad, a las narrativas, a la pluralidad, en definitiva, a la incardinación histórica de las identidades y comunidades.

Benhabib, quien desea un Habermas más «arendtiano»-de hecho, no en vano los orígenes del joven Habermas están marcados por las tesis de Arendt en La condición humana, especialmente por su consideración de la acción- ${ }^{49}$, «pensará con Hannah Arendt contra Hannah Arendt», prosiguiendo sus incon-

47 A. Wellmer, Etica y díalogo, p. 71.

48 * La diferencia decisiva entre la Crítica de la Razón Práctica y la Crítica del Juicio estriba en que las normas morales de las que habla la primera de ellas son válidas para todos los seres inteligibles, mientras que las de la última limitan su validez estrictamente a los seres humanos sobre la tierra.» Véase $\mathbf{H}$. Arendt, "Extractos de lecciones sobre la filosofía política de Kant», en La vida del espiritu, Madrid, Contro de Estudios Constitucionales, 1984, pp. 517-536, p. 518.

49 Véase J. Habermas, «Hannah Arendts, en Perfiles filosofico-politicos, Madrid, Taurus, 1975, pp. 200-221. El "perfil» dedicado a "Alfred Schütz" contiene tambiên referencias a Arendt, pp. 355-361. 
clusas reflexiones sobre el juicio ${ }^{50}$. Benhabib, al igual que Wellmer, radicalizará el rendimiento moral de las intuiciones de Arendt en el sentido de «... conectar la concepción aristotélica del juicio como un aspecto de la phrónesis con la comprensión kantiana del juicio como la facultad del "pensamiento representativo" $" 51$.

La «intuición valiosa» que se quiere rescatar es la de difuminar la oposición entre el juicio contextual -relativo al siempre relegado problema de la aplicación- y la moral universalista. En este marco, la concepción intersubjetiva. de la identidad cobra, de la mano de Arendt, una relevancia extrema: sólo si alguien nos escucha y nos entiende, sólo si alguien interpreta nuestras acciones, puede emerger la identidad del yo. No es soslayable la «inmersión» en una red interpretativa de relaciones. De ella depende la misma individuación. De esta manera, la única vía de acceso al «quién» del self es una «narrativa coherente de la que somos los protagonistas, pero no siempre los autores».

El tejido interpretativo invalida la idealidad de las construcciones apeliano-habermasianas al tiempo que inhabilita la primacia de la «forma». Las identidades «materiales» no pueden quedar al margen de la «moralización». La «mentalidad ampliada» que prescribe el juicio da entrada a la imaginación y a los sentimientos morales. Lo «moralmente relevante» ya no es lo meramente universalizable, sino aquella «situación o circunstancia que conduzca a la formulación de un deber moral entre los implicados» ${ }^{52}$. Eclosiona así, de la mano de la reversibilidad de perspectivas, otro concepto de validez intersubjetiva ligado, férreamente, al diálogo real.

Wellmer, en sintonía con esta recuperación del juicio, se rebelará de esta manera contra la tajante distinción habermasiana entre fundamentación y aplicación:

«Discrepando de Habermas, opino, por consiguicnte, que cl problema de la fundamentación tiene, en el caso dè la moral, el carácter de un problema de aplicaciốn; lo que está en juego en los discursos morales es la "aplicación" del punto de vista moral, ya sea a conflictos sociales concretos, ya sea a las situaciones individuales en las que se actúa» ${ }^{53}$.

Y de esta manera reafirma el trasvase hacia el juicio: «la razón práctica se manifesta como una facultad de juzgar moralmente». Remite a la reciprocidad y elimina los particularismos una vez que hacemos efectiva la estructura del reconocimiento mutuo. La identidad moral remite así al reconocimiento:

5) Véase S. Benhabib, wThe Judgement and the Moral Foundations of Politics in Hannah Arendt's Thought», Political Theony, vol. 16, núm. 1, febrero 1988, pp. 29-51. También compilado, en versión revisada, en Situating the Self, London, New York, Routledge, 1992.

st Op. cit., p. 30.

32 Op. cit., p. 31 .

${ }^{3}$ A. Wellmer, Etica y diálogo, p. 156. 
«... no podemos imaginar procesos de individuación cxitosa en los que no nos veamos, para decirlo kantianamente, confrontados con otras personas como "fines en sí mismos", o, parafraseando a Hegel, no podemos imaginar procesos de individuación exitosa que no se hallen inscritos en estructuras de reconocimiento mutuo» ${ }^{54}$.

El lenguaje opera como "vehículo» del reconocimiento, pero no puede suplantar a la base de un deber moral «afectivamente arraigado y dependiente de las condiciones de nuestro posible ser-nosotros-mismos» ${ }^{55}$. El fracaso o malogro del sentido moral revela que eel adiestramiento en las relaciones de reconocimiento mutuo" ha sido frustrado. Sin este soporte, sin una suerte de sensibilidad moral, «son inanes los meros argumentos ${ }^{56}$.

El resultado a conseguir es un tipo de conciencia moral en la que wel amor hacia sí mismo y la solidaridad con el prójimo, la autoafirmación y el reconocimiento de los demás» ${ }^{57}$ no sean incompatibles. Frente a los excesos cognitivistas de la ética discursiva, Wellmer se propone una reconsideración de la conciencia moral no reñida con su base motivacional empírica y que remita a un proceso de educación moral integral que recuse la abstracta formalidad del modelo habermasiano. Resuelve, de este modo, el consabido «déficit motivacional». La articulación de la virtud «cálida» de la solidaridad vuelve a ser aquí, como en el caso de Benhabib —quien también rescata las virtudes moral-transformatorias del discurso-, la piedra de toque para desbaratar el afilado corte entre la justicia y la felicidad.

El debilitamiento del trascendentalismo habermasiano supone relativizar la apelación al idcal. Lo importante es desarbolar cl "sinsentido", acabar con los «tratamientos desiguales fundamentados» para lograr mayores grados de autodeterminación fáctica - «el principio del progreso moral no consiste en el perfeccionamiento del sentido, sino en la supresión del sinsentido»- En este horizonte, la estimtación del juicio moral ${ }^{58}$ cobra una importancia clave, pues nos permite traer a colación el hecho de que:

«... en aquellas interpretaciones de la situación que han sido sustraídas a la discusión -incluyendo las interpretaciones sobre necesidades e intereses- suelen ocultarse por regla general el dogmatismo y el autoengaño morales. Tal rechazo de la realidad contiene siempre el germen de una vulneración a las personas. El imperativo de una elucidación comunicativa o discursiva de las interpretaciones de situaciones y de las comprensiones de sí mismo tiene, por tanto, no sólo el carácter de una obligación de racionalidad, sino el rango de una norma moral (por lo menos en lo que respecta a conceder el derecho de palabra a las personas involucradas)" ${ }^{59}$.

\footnotetext{
${ }^{4}$ Op.cit, p. 160 .

ss Op. cit., p. 162.

${ }^{s 6} \mathrm{Ibid}$.

${ }^{57} \mathrm{Ibid}$.

58. Op. cit., pp. 148 y ss.

sp. opit, p. 154.
} 
Nuestra conclusión es que, desde esta opción, que incluye la discusión y el tratamiento de las autointerpretaciones morales, que presta protagonismo a un modelo "ponderado" de identidad más allá de la estricta formalidad, sí es posible articular una crítica que desarbole el cúmulo de sobreentendidos que se ceban en una «situación ideal» que reniega de su ineludible procedencia histórica. El artíficio abstractivo queda desvirtuado por haber servido, demasiado a menudo, de coartada contra la dilucidación de las desigualdades.

\section{La intensificación hermenéutico-narrativa}

Wellmer renegaba de la «aureola cuasitrascendental» que acompañaba a los presupuestos inevitables del habla y la argumentación. El pecado de Habermas es haber olvidado la conexión insoslayable de lenguaje y tiempo. El modelo orientativo epistemológico, tomado prestado de Peirce, ha generado la marginación de la problemática hermenéutica al estar «cautiva de una concepción objetivista del conocimiento y la experiencia» que pretende anular con sus ideales «la historicidad y provisionalidad de todo sentido lingüístico» ${ }^{60}$.

La polémica con Gadamer vuelve al ojo del huracán -como siempre que median razón e historia-. La objeción hermenéutica vuelve a la carga y Wellmer nos indica su virtualidad: mostrarnos cómo kel consenso infinito de la comunidad de investigadores propuesto por Peirce presupone una neutralización del problema de la comprensión mutua», correlativa a la eliminación de «una mediatización hermenéutica del sentido», que allana el camino hacia la concepción de la comunidad como asingular encarnado en un plural» ${ }^{61}$-como sujeto trascendental que se forma en paralelo al progreso de la ciencia.

El lenguaje al que se había invocado como nueva piedra filosofal, al ser desposeído de su consustancial temporalidad y ser instalado en un nuevo «estado posthermenéutico», nos remite a una comunidad ideal de comunicación «depositaria de una verdad absoluta de interpretación ${ }^{62}$ que soslaya el frágil logro de la comprensión mutua. Wellmer nos muestra cómo la comunidad idealizada cstá «... más allá de la necesidad (y de los problemas de la mutua comprensión lingǘstica) y representa una intersubjetividad trocada en transubjetividad que "erradica" la "pluralidad constitutiva de los usuarios de signos" al concebirse falsamente como "un sujeto que, por haber alcanzado su madurez, se instala, por decirlo asî, en la verdad" ${ }^{63}$.

Apel, y en menor medida Habermas, «reincorporan» el absoluto en el fluir de la historia de la mano de la presuposición reconciliatoria que paga el precio de «eliminar incluso la temporalidad histórica». La estrategia idealizadora y consensual se revela falaz:

\footnotetext{
${ }^{6}$ Op. cit., p. 109.

${ }^{61}$ Op. cit., p. 114.

62 Ibid.

Op. cit., p. 115.
} 
«La comunidad ideal de comunicación habria superado, sí, el error, el disenso, la incomprensión y el conflicto, pero sólo a costa de una petrificación del lenguaje, de una extinción de sus fuerzas productivas, $o$ sea, a costa de la supresión de la forma de vida histórico-lingüística de la humanidad.»

Es includible prestar un mayor peso a la hermenéutica, al marco de referencia espacio-temporal, a la historia, en definitiva, a la necesidad «de una reapropiación, reformulación y reconstrucción hermenéutica de las intuiciones filosóficas certeras» ${ }^{64}$, con lo que «la idea de un valor-límite de la comprensión mutua ideal pierde todo su sentido». Los obstáculos a la comprensión mutua - los prejuicios, tal como señalaba Gadamer- son sus mismas condiciones de posibilidad. No necesitamos de la noción de una comunidad ideal de comunicación. El fantasma del relativismo sólo resulta amenazador desde una filosofía del absoluto ${ }^{55}$. Wellmer confluye con Bernstein al sostener que no hay «un punto arquimédico situado por fuera de nuestros discursos reales». «Desembarazarnos» tanto del absolutismo como del relativismo no significa ninguna traición a la idea de verdad. El reino de la transparencia donde lo múltiple se reúne sosegadamente en lo uno no existe ni existirá.

En otra parte ${ }^{66}$ Wellmer ya mostraba, al hilo de la consideración de la «objeción hermenéutica», sus recelos ante la estrategia abstractiva de la ética discursiva fundamentada pragmática-trascendentalmente. Si se desembocaba tan fácilmente en principios universalistas era porque, antes que nada, se había «abstraido todas las diferencias entre los hablantes» ${ }^{67}$. El sistema parecía así estar al servicio de «hablantes de una clase específica», «quienes, como sujetos morales, han completado prácticamente la transición a un nivel de abstracción de la pragmática universal». La identidad formal se quedaba con cartas debajo de la manga. Presuponer un nivel de abstracción como el «apropiado» para cuestiones morales implica, previamente, una transformación de la actitud hacia los otros y hacia uno mismo:

«... los intentos formales de justificación deben siempre hacer uso de presuposiciones que emergen del proceso educativo del hablante y que no pueden ser totalmente erradicados en los argumentos analítico-lingüísticos».

De lo que se trata es de atender a la «historia» de los «constituyentes» de tal proceso, a su elaboración en un doble sentido: la historia de las instituciones y revoluciones y el desarrollo de la conciencia moral y de la identidad

Op. cit., p. 122

os Op. cit., p. 123.

${ }^{60}$ A. Wellmer, «Practical Philosophy and the Theory of Society: On the Problem of the Normative Foundations of a Critical Social Science», en S. Benhabib y F. Dallmayr, The Communicative Ethics Controversy, Cambridge, Mass., MIT Press, 1990, pp. 293-328.

Op. cit., p. 327. 
del yo. Ambos aspectos ponen en cuestión que el asunto de la justificación en un nivel de abstracción tal sea acertado ${ }^{68}$.

Pero la intensificación hermenéutica debe tener sus efectos en la conceptualización de la comunidad. Benhabib es especialmente sensible a las críticas neoaristotélicas y neohegelianas que desafían a la ética discursiva ${ }^{69}$. De hecho, además de la «falacia racionalista» que comprometería una comprensión adecuada de los grados de contingencia, concreción y contextualidad presentes en las comunidades reales, se nos pone sobre aviso respecto a la tentación de que la intersubjetividad se resuelva en transubjetividad, debido a los «malos residuos» de la vieja filosofía de la historia y de la filosofía del sujeto. Hacer compatible la comunidad con una vocación pluralista es el reto a enfrentar.

Benhabib borra, sin más, la línea que separa lo «rcconstructivo» de lo «hermenéutico-narrativo». Las «reconstrucciones-racionales» son «relatos» -nosotros añadiremos, en lo que se refiere al «tratamiento racional-reconstructivo" de la conciencia moral, que tal «relato" es deudor de una "narrativa maestra» cuyo subtexto de género es «masculino»-. La única diferencia viene de sus grados de plausibilidad. Benhabib considera «preferibles» los relatos reconstructivos a los «deconstructivos» - los de Nietzsche, Foucault y Adornopor tres órdenes de razones: a) propician una metodología de la «documentación narrativa» que intenta desentrañar lógicas internas derivadas de los procesos de aprendizaje de los participantes; $b$ ) su noción de progreso es meramente formal y no apela a la dimensión semántica, $y$, por último, c) intenta sintonizar con las líneas de investigación social más fructíferas para dar cuenta del know how competencial.

No obstante, la conclusión es que «una justificación fuerte del legado de la modernidad cultural no es posible» y que la cuasitrascendentalidad que se le predica es un desvario: el programa reconstructivo no tiene una naturaleza diferente de los relatos hermenéuticos y deconstructivos. La diferencia proviene tan sólo del grado de verosimilitud. De lo que se trata es de que muestren «su capacidad para explicar, mediante narrativas inteligibles, complejos fenómenos». La modernidad, sus virtudes y sus vicios sigue estando en liza ${ }^{70}$. Benhabib acaba «intensificando hermenéuticamente» la programática habermasiana al poner sobre el tapete que los estándares a los que apela nuestra históricamente lograda reflexividad derivan de la comprensión hermenéutica. No podemos saltar sobre nuestra propia sombra.

Op. cit., p. 328

69 Véase S. Benhabib, «In the Shadow of Aristotle and Hegel: Communicative Ethics and Current Controversies in Practical Philosophy", M. Kelly (ed.), Hermeneutics and Critical Theory in Ethics and Politics, Cambridge, Mass., MIT Press, 1990. pp. 1-30. Incluido también en Situating the Self, ed. cit.

${ }^{73}$ S. Benhabib, Critique, Nom and Utopia, p. 270. Aquí sigue una interesante disertación sobre el lado oscuro de la modernidad y su estimación por parte de Adorno y Foucault. 


\section{La disputa sobre la comunidad: pistas y contextos}

El tratamiento crítico de la comunidad apeliana-habermasiana por parte de Wellmer y Benhabib apunta hacia el sentido destrascendentalizador de una «intensificación hermenéutica». El asunto es que no existen atalayas "privilegiadas fuera o por encima de la historia desde las que contemplar la vida humanas ${ }^{71}$. El investigador es siempre, aunque virtualmente, participante en un diálogo, incluso cuando «observa y critica». Las afirmaciones de McCarthy se suman a las de Wellmer y Benhabib en el trasfondo del problema del relativismo y la apertura de hostilidades entre las slíneas contextualistas» y «las universalistas» ${ }^{72}$. El asunto es que a la luz de posiciones de la «crítica interna» parece haberse firmado una tregua: el universalismo puede convivir cualificándose de «interactivo» con el juicio contextual. Los procedimientos abstractos permiten dar cobijo al «potencial de particularización local», en opinión de McCarthy. No tiene, sentido, en suma, «oponer disyuntivamente» «... normas y valores descontextualizados, en tanto generalizados, por una parte, y juicios contextualizados, cn tanto particularizados, por la otras ${ }^{73}$.

La diferencia que detecta McCarthy entre el trascendentalismo clásico y el programa reconstructivo racional es que ya no queda nada de las «pretensiones fuertes y a priori que realiza el proyecto kantiano", pues ol tratamiento de la reconstrucción de las competencias de la especie es hipotético y, por lo tanto, sólo comprobable a posteriori. El falibilismo marca la diferencia. Pero la objeción de McCarthy a la pragmática universal nos devuelve a la tensión ideal-real: «ipor qué la reconstrucción de estructuras putativamente "universales e ineludibles" de comunicación ha de comenzar con este caso idealizado ${ }^{74}$, el de la acción comunicativa "pura", que es más bien la excepción y no la regla?»

La misma objeción parece operar para los estadios «superiores» de la escala kohlbergiana referida al desarrollo moral, pues una vez que arribamos a la postconvencionalidad, el rendimiento externalista se quiebra y devuelve a la hermenéutica todo el protagonismo. No tendría sentido, por ejemplo, sostener la superioridad de un eformalismo postconvencional» sobre un "contextualismo» igualmente «postconvencional». La participación hermenéutica integra «el distanciamiento térico y crítico" y no lo excluye, pues siempre tenemos algo que aprender de los otros en el medio del «diálogo». Todos lo esfuerzos de la «crítica interna» convergen en moderar los excesos idealizadores y tras-

"T. McCarthy, «Razón y racionalización: la "superación" de la hermenéutica por Habermas», en Ideales e ilusiones, p. 140.

${ }^{72}$ Véase T. McCarthy, "La pragmática de la razón comunicativa», en Isegoria, núm. 8, actubre 1993, pp. 65-84.

"Art. cit, p. 81.

${ }^{74}$ T. McCarthy, «Razón y racionalización; la "superación" de la hermenéutica por Habermas", cn ldeales ellusiones, p. 144. 
cendentalistas - la estrategia de McCarthy, a decir de C. Thiebaut, es la de «pragmatizar» la teoría crítica- ${ }^{75}$ para devolvernos a una hermenéutica reconciliada con el pathos crítico. Este esfuerzo tiende hacia la recuperación de la pluralidad en la comprensión de la intersubjetividad, por lo que la «humanidad reconciliada (de una comunidad ideal de comunicación) ${ }^{76}$ queda desechada como disfraz del viejo absoluto. La indeterminación interpretativa no puede ser soslayada. La historicidad media cualquier reapropiación de la verdad filosófica.

El error de Apel residía en el sustrato kantiano-peirciano, pues el modelo de la «anticipación» se forja conforme al modelo de la física: «la ultimate opinion de los investigadores hallaría su expresión idónea en un lenguaje definitivo y en un sistema estable de enunciados» ${ }^{77}$. Pero «el enunciado filosófico contiene un índice con el que hace referencia al tiempo y al lugar histórico en que ha sido pronunciados ${ }^{78}$. El malentendido de la comunidad ideal remite a una mala comprensión del lenguaje como medio transparente, ajeno a la historia. Un medium semejante supondría realmente un «más allá del lenguaje». No se ve necesidad alguna, a la luz de lo considerado aquí, de apelar a la comunidad ideal/universal de comunicación de seguir prendidos al absoluto. De lo que se trata es de sortear «la sombra perenne de un absolutismo que pretende fijar la verdad en un punto arquimédico situado por fuera de nuestros discursos reales» ${ }^{79}$.

La conversación real gana la partida al «diseño conversacional» ${ }^{80}$. El talón de Aquiles del programa apeliano-habermasiano es que «ticne que apelar a una situación ideal de comprensión mutua para explicar la conexión entre racionalidad y verdad» ${ }^{81}$. Tal situación pretende ser un «ideal extraído de la realidad», pero esto que podía ser su atractivo «seductor» «se vuelve contra ellas mismas haciéndolas vulnerables e inaprensibles». Wellmer desautoriza la referencia al «reino de los fines»: en él no hay lugar para los conflictos morales, dado que el problema de la comprensión mutua queda desactivado al instaurarse «una unidad sin fisuras». La pluralidad de los sujetos se anula al presuponerse un «ideal haberse comprendido ya», un «estado donde se han dispersado para siempre las tinieblas que existen entre, y dentro de, los sujetos». Sin las tinieblas ni siquiera tendríamos necesidad de acudir al lenguaje. El resultado es que, con el "trasvase al juicio» y con la sintensificación herme-

75 Véase C. Thiebaut, «¿ Una pragmatización de la teoría crítica? (El doble gesto de Thomas McCarthy)", en Isegoria, núm. 5, mayo 1992, pp. 167-176.

7t A. Wellmer, Ética y diálogo, p. 120.

"Op. cit., p. 122.

${ }^{78}$ Op. cit., p. 123. El «índice» al que se refiere Wellmer remite al sentido que McCarthy otorga a la kindexicalidad" y epracticidad" puestas de relieve por la etnometodología de Garfinkel. Véase «La prágmática de la razón comunicativa», en Isegoria, núm. 8, pp. 66-74.

${ }^{79}$ A. Wellmer, op. cit, p. 123.

${ }^{2 a}$ Véase M. Walzer, «A Critique of Philosophical Conversation», en M. Kelly (ed.), Hermeneutics and Critical Theory in Ethics and Politics, pp. 182-195.

"Art. cit., p. 124. 
néutica» -que parece llevar pegada a los talones al "giro narrativo"- nos hemos apeado de la comunidad cuasi-trascendental.

Encadenando las observaciones de Benhabib, Wellmer y McCarthy -copartícipes del programa teórico crítico- hemos ido descendiendo de las alturas celestiales de la comunidad ideal a la tierra - a la atención a las comunidades reales que remiten a la pluralidad y a la inevitabilidad del conflicto-, hemos vislumbrado la tensa ambivalencia de la posición habermasiana que hegelianamente aspira, vía la reformulación del diagnóstico weberiano de la modernidad, a aproximar lo real y lo ideal estimando en mucho los progresos históricos de la moralidad y la legalidad.

Por el contrario, la posición crítica que hemos delineado apunta a una "cura destrascendentalizadora" cuyo tratamiento consiste en prestar un mayor peso a una hermenćutica que integre polémicamente el distanciamiento crítico y la comprensión mutua, y que, por tanto, opte a protegerse tanto de malos acuerdos como a propiciar «buenos desacuerdos», relativizando las premisas consensuales al considerar el hecho de la pluralidad humana y la indeterminación operativa en el sucederse de las interpretaciones. En este contexto, el individuo adquiere un nuevo protagonismo, pues él será el encargado, nada menos, que de «juzgar» con «buen tino». La Bildung del sujeto moral se vinculará a las virtudes moral-transformatorias del discurso, con lo que las autocomprensiones individuales necesitarán ser explicitadas. El modelo de identidad moral habermasiano, magro en exceso debido a la estrategia ideal-abstractiva, tendrá que ser revisado a esta nueva luz.

Finalmente, otra virtualidad del tránsito de la idealidad del «diseño conversacional» a la "conversación real» reside en la posibilidad de integrar en el diálogo a los escéptico-relativistas - los denostados postmodernos- ${ }^{82}$, empeñados en celebrar la pluralidad, y a los comunitaristas - algunos de ellos decididamente anclados en la nostalgia de lo premoderno- ${ }^{87}$, reacios a desprenderse de sus visiones de la vida buena, aunque algunos como Taylor opten por instalarse

${ }^{2}$ De las criticas postmodernas a Habermas destacamos la de Vattimo, quien le achacaba no asumir con radicalidad la historicidad, la desatención de lo «sustantivo» frente a la primacía de la forma, los excesos metaéticos, el «ideal de autotransparencia» que opera trasladando la metafisica de la subjetividad al plano social, el que no haga justicia a la sfinitud» del individuo emmascarándola en su propuesta de un «yo» intersubjetivamente constituido qua comunidad unánime, el sesgo epistemológico y objetivista que desestima el juego de interpretaciones, el trascondentalismo no atenuado por el procedimentalismo... Críticas que formuladas en otro tono -y dejando al margen las propuestas «positivas»- son las mismas que las de la crítica interna, pues provienen de una vocación hermenéutica, en este caso, más radicalizada y no tan atenta a salvaguardar la normatividad común. Véase G. Vattimo, Más allá del sujeto, Barcelona, Paidós, 1986; «Dialéctica, diferencia y pensamiento débils, en G. Vattimo y A. Rovatti, El pensamiento débil, Madrid, Cátedra, 1988.

${ }^{83}$ El caso paradigmático es Maclntyre y su añoranza aristotélico-tomista. Véase, además de Tras la virtud, A. MacIntyre, Tres versiones diferentes de la ética, Madrid, Rialp, 1992. 
en la modernidad ${ }^{84}$. Si la hermenéutica es la nueva «koiné común» ${ }^{85}$, si el pluralismo y la tolerancia, sin renunciar al mínimo normativo del respeto a todos, se anudan, es posible abrir nuevas vias de conversación antes atascadas por visiones estrechas de la propia autoidentificación intelectual. El caldo de cultivo del imperativo, para decirlo con Rorty ${ }^{\circledR 6}$, de «mantener la conversación» es la «diseminación» hermenéutica que ha hecho fortuna en nuestra época. Lo que prescribe la «humilde» hermenéutica es, precisamente, que nunca habrá una interpretación definitiva. Dejar atrás la «obsesión "epistemológica" de Habermas», a lo que nos anima Javier Muguerza, es esencial para abrir las puertas a la convivencia de los distintos «credos» éticos ${ }^{87}$. El modelo de la tolerancia religiosa es pertinente aquí y no la camisa de fuerza de la resolución consensual.

Wellmer, Benhabib y McCarthy nos reenvían más allá del «objetivismo y del relativismo». Eso no significa denegar las «divergencias» ni los «disensos» fundiendo a todas las posiciones en un todo indiferenciado, sino, simplemente, consentir en que es posible seguir hablando - deconstruyendo y reconstruyendo- con el fin de lograr frágiles. comprensiones mutuas. Lo indudable a estas alturas es que el paradigma dialógico está bien instalado entre nosotros. El problema es «cómo, en qué forma se podría realizar el ideal de autodeterminación individual y colectiva de individuos, grupos y pueblos» ${ }^{88}, \sin$ minimizar las fricciones entre los modelos de autonomía individual y colectiva, tal como hace Habermas al acudir con premura a la varita mágica del consensualismo que redime todo conflicto. McCarthy, a este respecto, se decanta por una salida pluralista que avale:

«una esfera pública cuyas instituciones y cuya cultura encarnaran esta diversidad, lo cual sería... un ideal más realista que otro que encarnara, de la forma todo to destrascendentalizada que se quiera, la noción kantiana, insuficientemente contextualizada, de voluntad racionals ${ }^{89}$.

${ }^{84}$ Taylor es sobre todo un neo-hegeliano dispuesto a defender a la modernidad no de sus detractores, sino de sus defensores, esto es, contra el mismo Habermas y su intento de poner al margen la intensa conflictividad moderna. Todo esto lo podemos encontrar en los primeros capitulos de Sources of the Self, Cambridge, Cambridge University Press, 1989.

${ }^{2}$ Es Eta es la expresión que utiliza Vattimo para señalar nuestra instalación hermenéutica irreductible. Véase «Ermeneutica, nuova koinè", en G. Vattimo, Etica dell'interpretazione, Tujin, Rosenberg \& Sellier, 1989.

${ }^{36}$ Rorty en su ya archifamoso libro La filosofía y el espejo de la naturaleza -Madrid, Cátedra, 1983 - concluía transitando de la epistemología a la hermenéutica al decretar el final de la «filosofía de la representación». Su indicación final venía a apuntalar el carácter «edificante» de la conversación y la necesidad de proseguirla.

*7 Véase J. Muguerza, De la conciencia al discurso: ¿un viaje de ida y vuelta? (Algunas reflexiontes en tomo a la teoría de los usas de la razón práctica de Jürgen Habermas), en J. A. Gimbernat (ed.), La filowofia moral y politica de Jürgen Habernas, Madrid, Biblioteca Nueva, 1997.

${ }_{38}$ A. Wellmer, «De la dialéctica entre modemidad y postmodemidad: crítica de la razón después de Adomo», en Sobre la dialéctica de modenidad y postmodenidad, Madrid, Visor, 1993, p. 109.

T. McCarthy, «El discurso práctico: sobre la relación de la moralidad con la política», en Ideales e llusiones, p. 212. 
A lo que aspiramos es a que la comunidad se decline en plural y a que la intersubjetividad no sea trastocada en transubjetividad a causa de la presión de un modelo, el habermasiano, que aúna comunidad y consenso. Para ello nos entregamos a las tareas de des-fundamentar, des-idealizar y des-trascendentalizar la misma idea de comunidad. 